Title: Understanding grief in a time of COVID-19 - a hypothetical approach to challenges and support

First author (corresponding author): Chao Fang (ORCID ID: 0000-0002-7072-6072)

Affiliation: Centre for Death and Society, University of Bath, UK

Address: 3 East, University of Bath, BA2 7AY, Bath, United Kingdom

Email: C.Fang@bath.ac.uk

Second author: Alastair Comery (ORCID ID: 0000-0002-6475-3218)

Affiliation: Department of Social and Policy Sciences, University of Bath, UK

Address: 3 East, University of Bath, BA2 7AY, Bath, United Kingdom

Email: abc45@bath.ac.uk 


\section{Understanding grief in a time of COVID-19 - a hypothetical approach to challenges and support}

\section{Abstract}

- Purpose

This article develops preliminary understandings of loss and grief at both an individual and collective level following the COVID-19 outbreak. This allows for insights into the possible challenges and support for grieving and bereavement in facing unprecedented disruption and uncertainty. Ultimately, it explores avenues for better bereavement support.

- Design/methodology/approach

By examining relevant media and academic discourses, the authors analyse and envisage challenges and support for those experiencing loss during COVID-19. The discussion revisits and further relocates the ideas of good and bad deaths in the context of increased social constrains and inequalities. Further, two pairs of contrasting hypotheses are proposed to examine the impacts of COVID-19 on both bereaved individuals and society as a whole during and post the outbreak.

- Findings

The discussion captures a mixed picture of grief and bereavement, which highlights the importance of timely, holistic and continuous support. It is found that individual and collectives express diverse needs to respond to deaths and losses as a process of meaning-making. Further the significance of socio-cultural environments also become evident. These findings highlight community support during COVID-19 and further promote a grief literate culture as imperative to support individual and collective needs when confronted with loss and grief. 
- Originality/value

This article provides timely and comprehensive accounts of possible challenges and support both for individual and collective experiences of loss and grief. These understandings could facilitate further research, informing better practice and policy decisions to support the bereaved in the context of COVID-19 and other disruptive world events.

Key words: COVID-19, pandemic, bad death, grief, bereavement support, compassionate communities

\section{Introduction}

COVID-19 has claimed a significant number of lives worldwide (World Health Organisation, 2020). First reported in Wuhan China in December 2019, this newly discovered coronavirus is highly infectious. Until February 2020, China had remained the epicentre. However, the virus 
soon spread to the rest of the world causing significant economic disruption, social restrictions and a sharp increase in the number of deaths. On $11^{\text {th }}$ March 2020, the World Health Organisation declared the COVID-19 a pandemic. Although the fatality rate varies between countries and care settings due to disparities in care quality and resources, the vast number of lives lost in this pandemic could widely affect individuals as well as communities and society as a whole.

Given the unprecedented challenges, uncertainties and isolation resulting from COVID-19, it is not unreasonable to speculate that death, dying and bereavement could be greatly impacted. As widely reported by media outlets, many patients across the world have had to die alone without the company of their loved ones, at home, in hospitals, hospices or other care facilities. Frustration and even desperation may be faced by the survivors who are unable to say goodbye to, care for, or pay their last respects to their loved one (i.e. Ramsay, 2020). Further, lockdown and social distancing rules may strongly restrict bereaved people's capacity to seek emotional closeness and social connectedness when facing the above experiences of loss and grieving. Such bad experiences (Holst-Warhaft, 2000; Valentine, 2009), may trigger unbearable sorrow, regret and even anger for bereaved people and could cause further difficulties in coping with loss in their ongoing lives. Despite the extraordinary levels of social disconnection and constraints seen during COVID-19, bereaved people may receive more support, both practical and emotional, from kin, friends, neighbours and the wider society. These positive and supportive responses were also seen at a more collective level through the heorisation of deaths and public mourning. As such, responses to losses and deaths in the context of COVID-19 are not only individual tasks but also societal. To begin to develop nuanced understandings of grief and bereavement during and post the pandemic, this article 
situates a discussion of loss and grief in the context of COVID-19. Since this article is written during the pandemic when primary data collection is difficult and secondary academic data is limited, the authors examine available evidence from media coverage and existing literature. Challenges of dealing with loss and the resultant support frameworks are hypothesised and explained at both an individual and societal level. This approach aims to guide future research, grief care and bereavement support responses in light of the unprecedented COVID-19 pandemic

\section{Good and bad COVID-19 deaths}

Death and dying in the context of pandemics can be highly distressing and disruptive for both individuals and society (Bigelow and Hollinger, 1996; Lipton, 2017; Holst-Warhaft, 2000). Resonating with other pandemics, such as HIV and Ebola, COVID-19 may cause not only severe physical damage and mental distress to individuals but also disorder and dysfunction within society. Exceptional to COVID-19 is the severity of virus transmission. The unprecedented levels of social restrictions imposed onto bereaved people could undermine people's autonomy and the support resources available to them in the face of death and dying. Furthermore, Covid-19 deaths are likely to violate predominant public and healthcare discourses about 'good death', which favour a pain-free and smooth dying process emphasising holistic wellbeing, family presence, autonomy and dignity (Meier et al., 2017). Despite bad death prevailing in this pandemic, some deaths have been constructed in media and public discourses as heroic and thus good, as a collective means to justify losses and alleviate emotional costs during Covid-19. 


\section{Painful death}

Contracting COVID-19 may cause debilitating complications with symptoms including pneumonia, dyspnoea, acute cardiac injury and other secondary infections (i.e. Huang et al., 2020). Many patients have reportedly experienced tremendous discomfort, including severe difficulties in breathing, having to rely on ventilators during their final moments. In some circumstances, especially during the early stages of outbreak, appropriate care for patients was not available due to limited medical resources and knowledge (Monella, 2020). Some doctors have even had to prioritise ventilators and other care resources to focus on those with the best chance of survival, leaving the older and the fragile little room to seek relief (BBC News, 2020f). Therefore, patients with the virus could die with extensive physical deterioration, discomfort and distress. Pain of this nature could be further escalated by forced separation from loved ones resulting from the strict prevention and control measures. A tragic story was recorded in which a victim "cried out for his family before dying alone" (Ward, 2020). Death in this manner reflects the parameters of lonely death, which may be more broadly representative of the dying experience that patients with COVID-19 or other terminal conditions may suffer.

\section{Lonely death}

Dying patients during the COVID-19 outbreak could face increased risk of suffering lonely death, an experience of not only dying physically alone but also in a marginalised status of being socially isolated and emotionally lonely (Turner and Caswell, 2019). When experiencing physical deterioration and having lost the capacity to care for themselves, dying patients could be forcedly barred from seeking and gaining support and care from their loved ones due to COVID-19 quarantine measures. Family support at the deathbed can often forge 
cherished moments that enable the dying person and their loved ones to gain comfort and to reaffirm their family bonds (Lawton, 2000). These experiences may allow for a meaningful passage to transform and heighten their bonds not only through religious or spiritual norms but also simply by physical contact and language, such as a kiss or the words 'I love you' (Pace and Mobley, 2016). These symbolic and intimate interactions may be difficult, even impossible under the contagion control measures. Although, as reported by the media (i.e. Siddique and Marsh, 2020), many care providers have relied on video calls to help families say farewell to their loved one during the outbreak, these interactions can be greatly limited. A bereaved son from the UK conveyed his frustration with the virtual farewell to his mother (ITV News, 2020b):

I wanted to go there but I wasn't allowed and that's the hardest thing, just not to be able to comfort her and stroke her head and kiss her and just to be able to hold her hand.

Dying with extensive physical pain and emotional distress and also with little support can be extremely undignified (Seale, 2004). Although some countries, such as the UK, relaxed rules restricting family members to see their dying relatives in care facilities (BBC News, 2020b), many people had already died unaccompanied by their family. Despite regulation changes, the lack of necessary personal protection equipment in care facilities meant that patients may still have died while experiencing loneliness.

The risk of experiencing a lonely death could be further escalated for those who had been vulnerable and disadvantaged before the outbreak, including older people living alone or in facilities. Cited by the BBC in her interview with local Television, Spanish Defence Minister 
admitted that "the army, during certain visits, found some older people completely abandoned, sometimes even dead in their beds" (BBC News, 2020e). People from low-income backgrounds and ethnic minority groups have also been reportedly the worst hit communities by COVID-19 related deaths in numerous countries (i.e. Public Health England, 2020; Eligon and Burch, 2020). Social inequalities have greatly contributed to the high death rates among those isolated and disadvantaged. Without sufficient policy consideration and social support, these deaths could be both lonely and also marginalised, questioning social responses and broader structures in the context of the pandemic (Kellenhear, 2007).

\section{Unexpected death}

It has been recorded that many people across the world have died unexpectedly as a result of COVID-19. Patients can die within weeks and even days after contracting the virus. In the face of sudden deaths, bereaved people are often left little time to face and prepare for their loss. Research has found that the tragic and unexpected loss of a loved one could place survivors at increased risk of experiencing a sense of incomprehension, helplessness and guilt (Valentine, 2010; Holst-Warhaft, 2000). This loss may also acutely question bereaved people's taken-for-granted life and family and social relationships, further challenging their sense of meaning and identity (Handsley, 2001). The unexpectedness of loss is even more pronounced in the face of premature deaths. Media and public discourses have strongly portrayed COVID19 as a serious threat to the lives of the elderly and fragile, despite deaths of children and those from younger generations being recorded. Child deaths are often considered untimely, unnatural therefore particularly bad, likely leaving the bereaved family and broader society struggling to justify the loss (Walter, 1996). The pain and isolation attributed to COVID-19 
could further intensify the debilitating nature of child loss, as conveyed in an interview about a teenage victim who died suddenly after contracting the virus in the UK (ITV News, 2020a):

He was a young boy, 13 without his mother, without any of his siblings on his deathbed in the last moments. That's very hard to understand and digest...

\section{Heroic death}

Deaths and crises confronted in this pandemic and other catastrophic events, such as disasters, wars, terror attacks and pandemics, could be greatly disruptive to both individual lives, as well as society (Walter, 2020). Thus, constructing good deaths at a collective level could become particularly important, providing meaningful scripts to support individual losses and to reinforce social solidarity (Seale, 1995). Heroic deaths have been constructed and promoted by media and public discourses during this pandemic, to honour healthcare and other essential workers (Atlani-Duault, et al., 2020). One example concerns the martyrisation of Dr Li Wenliang and his colleagues, the whistle-blowers of the outbreak in China (BBC News, 2020a). The sacrifices of many other key contributors, who have lost their lives to save and help others, have also been honoured in their respective countries. The recognition of their professional identity and selfless spirit can offer meaningful reminders of hope and wholeness to society as an entity (Goren, 2007; Walter, 2020).

\section{Challenges and support in facing grief and bereavement}


Significant challenges and risks when dealing with death and grief could be expected at both an individual and societal level during and post COVID-19. As outlined above, deaths during this pandemic could often be 'bad', violating the modern craft of dying that emphasises individual autonomy, holistic support, preparedness and physical togetherness with family (Walter, 2020). Due to lockdown, social distancing and other new restrictions, bereaved people may find their needs for grieving and bereavement largely unattended. The increased social inequalities seen in this pandemic may contribute to or even exacerbate barriers for grieving and bereavement. These difficulties could be particularly evident for vulnerable and disadvantaged individuals and is likely to restrict their access to external support (Bear, et al., 2020). In contrast, support at a community level may become more available and vibrant during COVID-19 (Office for National Statistics, 2020). Grassroots support and mutual understandings were seen in local settings, while public mourning has emerged across the world. Although this increased support may help bereaved people confront and deal with their grief and bereavement, it is unclear to what extent and in what circumstances this support could impact bereavement experiences. Little academic data has been generated thus far to gain explicit understandings. Therefore, a hypothetical approach is adopted to draw on available media and academic resources to evaluate possible challenges and support for grief and bereavement both at an individual and collective level.

\section{Individual grief}

Previous pandemics, such as HIV and Ebola, not only caused wide spread deaths and fear but also created invisible barriers for survivors to exercise their individual agency to cope with their loss (Bigelow and Hollinger, 1996; Lipton, 2017). Similarly, the COVID-19 pandemic could amplify the conflict between individual needs and public health interests due to adverse social 
restrictions and inadequate support. Some bereaved people may feel more powerless and isolated and as such grieving for their loved one could be difficult or even impossible. However, informal support from kin, friends, neighbourhoods and colleagues may remain available or become more accessible at this difficult time. Given the large global death toll, victims' families and friends may also form and share symbolic bonds, as seen in bereaved families of deceased veterans (Walter, 2020). To further explore the possible impacts of COVID-19 on individual grief, two contrasting hypotheses are proposed to examine relevant media coverage and research: COVID-19 can make grieving harder or easier.

\section{Hypothesis 1: Grieving and bereavement are harder in the context of COVID-19}

Bereaved people in this pandemic may face isolation and incompetence due to lockdown and other control measures. As mentioned above, bereaved people could struggle to find meaning while confronting a bad death of their loved one which may be painful, lonely, unexpected or a combination of these. The increased social restrictions seen during COVID19 could further compound the difficulties in bereaved people's experiences of meaningmaking. Thus, grieving for their loved one could be difficult or even impossible. This poses two questions, does this sense of powerlessness and helplessness in grieving persist even after the death? Does it obstruct bereaved people from seeking comfort from others and developing mutual support networks to cope with grief? The following interview quote may allude to one possible answer (ITV News, 2020b):

We haven't been able to see each other, we haven't been able to comfort each other, or grieve properly. We are all isolating. We can't go out, can't comfort each other. 
In response to the tight control measures, bereaved people may experience limited agency to deal with their grief following the death of their loved one. Funerals and ceremonies have been cancelled, postponed or significantly altered (i.e. Horowitz and Bubola, 2020; McCann, 2020). For example, funerary rites may have to be minimalised or held online. These restricted and virtual interplays could hardly replace normal face-to-face interactions and physical memorial activities, which involve not only close family members but also those from broader social networks. A hug, a conversation with other mourners or a sacred site of religion may allow for and even heighten special emotions and meanings for bereaved people (Davies, 2017; Walter, 1996). Therefore, bereaved people may find the absence or minimality of funerary rites distressing ( $O^{\prime}$ Rourke, et al., 2011). What may be more distressing is the absence of an ongoing structure for mourning; not being able to say goodbye to their loved one, agonising over being separated from others at the funeral and not being able to visit the grave afterwards.

Public recognition of some people's loss and grief may also be absent during the outbreak, as not everyone's loss and grief would be automatically recognised. As such, feeling unentitled and unsupported to publicly share and cope with grief may cause disenfranchisement (Doka, 1989). As a result of their increased chances of encountering deaths in the workplace, healthcare workers may experience grief in relation to deaths of individual patients, colleagues or the loss of life in a more collective sense. As such, they could be at heightened risk of experiencing disfranchisement of grief. Their professional identities may create invisible barriers making them fail to acknowledge and cope with their grief (Aloi, 2011). This may be further exhibited by the lack of language for grief and concerns regarding professional 
boundaries (Lathrop, 2017). Their disfranchisement could be further amplified by health workers' agonising life and death decisions, prioritising care for limited patients due to restricted medical resources. A doctor conveyed his stress to BBC News (2020f): "Seeing people die is not the issue. We're trained to deal with death... The issue is giving up on people we wouldn't normally give up on". Feelings of guilt, powerlessness and shame may be so strong that individuals' personal psyche, moral values and professional identities could be severely challenged (Dean et al., 2019). Another high-risk group for disfranchised grief is bereaved family members whose loss and grief are infrequently recognised in public discourses during the outbreak. For example, a bereaved daughter felt forgotten and heartbroken when facing her mother's death only as a 'figure' in official data (BBC News, 2020d):

She was one of the figures of death. And it's heart-breaking because to everyone else, that's just a number but that number was my mum.

Some bereaved families could experience more hardship when their loved one's death is not officially recorded in the data of COVID-19 victims (Booth, 2020). They may feel they are unentitled to access sympathy, condolence and other resources for COVID-19 victims and as a result, they may experience marginalisation in facing their grief.

Marginalisation could further exacerbate the difficulties of bereaved people facing disadvantaged deaths. As mentioned above, disadvantaged deaths may grow in black, ethnic minority and older groups as a result of increased inequalities, such as racism and social neglect during COVID-19 (Bear, et al., 2020; Public Health England, 2020). Grief-stricken families of these victims may have to face difficulties in understanding and justifying the death 
of their loved one. For example, some bereaved African American families questioned the racial bias in COVID-19 treatments as part of meaning-making for their loss (Eligon and Burch, 2020). Inept communication and cooperation between care providers and public health authorities may also contribute to disadvantaged deaths, thus bereaved families may further question broader social structures. As seen in Spain, a group of bereaved adult children challenged the bureaucratic barriers in care homes to seek a clearer picture of their parents' death (Bachega, 2020). How to justify these disadvantaged deaths may remain a challenge for the bereaved in the longer term, requiring further negotiations to contest to the meanings of their loss (Holst-Warhaft, 2010).

There may also be marginalisation of bereavement in the context of geographical inequalities, leaving many bereaved people little access to support. One pandemic is essentially many epidemics; thus, challenges and available resources for grief and bereavement during COVID19 could vary between countries and regions. Many post-industrial societies have developed multifaceted responses to offer varying degrees of support for bereaved people. These resources could both continue and further develop during and post the outbreak, including counselling services, psychotherapy, charity support, social policies and other socio-cultural norms (i.e. Cruse Bereavement Care, 2020; American Psychological Association, 2020). Conversely, bereaved people in societies with limited resources and infrastructures may struggle to comprehend their loss and access relevant support (Fang, 2019).

In addition to increased social restrictions and inequalities, particular types of loss could make grieving and bereavement harder. Child deaths as a result of COVID-19 could be extremely difficult for parents, who may find their grief particularly challenging in the face of unnatural, 
untimely and bad death. Living in a society where premature deaths are no longer predominant, bereaved families may find limited support from social norms and religious values, to make sense of and give meaning to their child's death (Walter, 1999). The COVID19 outbreak may further suppress their agency and resourcefulness when dealing with grief. Child deaths could also fundamentally challenge parents' identity and further destabilise family structures (Riches and Dawson, 2000). Furthermore, given the highly infectious nature of COVID-19, some people may lose multiple individuals in their family and immediate social circles. Therefore, they may experience intense emotional distress and other practical or financial issues if one or more family members has died.

Hypothesis 2: Grieving and bereavement are easier in the context of COVID-19

Despite numerous issues and risks faced by the bereaved, people experiencing grief and loss may receive more support at this difficult time. There is significant evidence of increased support in families, neighbourhoods and wider social and public spheres, raising the question, does this increased support make grief and bereavement easier? The answer to this question is complicated in light of bereavement as a diverse experience embedded in ongoing life. Central to understanding the diverse experiences of bereaved people in this pandemic is to examine the quality and continuity of support both in the short and longer term.

Some people's family resources and social capital could grow in the face of loss and forced separation during COVID-19. As widely seen, family and friends have provided emotional and social support via video calls and social media. Neighbourhoods have also come together to offer practical and emotional support for isolated and vulnerable residents (National Office for Statistics, 2020). Even when their individual agency was challenged by the lockdown and 
social distancing rules, some people exploited limited resources to access family bonds and community spirit to cope with loss. Funerals for example, have had to be minimalised during the outbreak, but some families could have experienced a heightened sense of intimacy and solidarity through a 'tiny' family-organised funeral (Alcorn, 2020). This may have enabled kin to focus more on the funeral itself and thus better face and make sense of loss. In addition, condolence paid to COVID-19 victims from the wider society may have provided bereaved people a sense of sympathy and comfort. The identification with other mourners of COVID19 victims could also help them enfranchise their grief, further contributing to developing mutual understandings and a sense of belonging in the face of meaninglessness and isolation. For example, a UK family invited other bereaved families of COVID-19 victims to use a yellow heart to visibly signal their loss and share stories of their loved one (BBC, 2020g). In public domains, governmental bodies and professional organisations also adopted sympathetic and flexible approaches to extend their support for bereaved people. This informative and instructive support could help guide bereaved people to deal with the multifaceted issues associated with loss and grief, including financial difficulties, death registration, emotional stress and other challenges and risks. Nonetheless, not every bereaved person can access increased support and experience positive responses. Their grief and bereavement may reflect their personal circumstances and broader social contexts.

The immediate support seen during the outbreak suggests the importance and the potential of continuous care for bereaved people in the longer-term. After social distancing rules are lifted and typical social order is resumed, informal support from family, friends, colleagues and neighbours may become more physically accessible for bereaved people. Formalised social and health care systems may continue and even expand their services, especially in 
societies with well-established welfare and healthcare frameworks. In the longer-term, it is important to ensure professional care of psychotherapy and clinical interventions remain available where needed, to help bereaved people cope with their loss and grief. It is however equally crucial to avoid over-emphasising pathological aspects of grief and heavy reliance on therapeutic frameworks (Valentine, 2008; Walter, 1999). That said, bereaved people are inherently resilient in responses to loss, tending to adopt and revise the status quo by seeking their own means of grieving (Bonanno, 2004; Valentine, 2009; Fang, 2019). Even in extremely difficult circumstances, they may still be able to transform their grief to challenge and reshape social structures (Holst-Warhaft 2010). Bereaved people may draw upon various socially accessible tools, such as language, arts and other creative means, to reconstruct meaning as part of their ongoing lives (Neimeyer, 2011; Walter, 1996; 2012). Meanwhile, the shared experience of loss may also prompt self-help groups both online and face-to-face in the longer term. This reciprocal support could enable bereaved people with similar experiences during COVID-19 to develop mutual understandings and a sense of belonging, thus helping them better make sense of their loss and rebuild meaningfulness both individually and collectively (Fang, 2019; Valentine, 2017).

\section{Discussion: mixed experiences of grief and bereavement}

It is not straightforward to say if the COVID-19 pandemic has made grieving and bereavement harder or easier. The answer is rather conditional, showing the complexity and fluctuation of such experiences. The COVID-19 outbreak and resultant quarantine enforcements imposed increased social restrictions. These could consequently create new barriers, suppressing bereaved people's autonomy and restricting the available resources to deal with and recognise loss and grief. Existing issues of inequality may also be amplified during the 
pandemic, adding further difficulties for some to justify and adapt to their loss. These new and pre-existing social issues could further debilitate people in the face of particularly 'bad' deaths, making their grieving and bereavement even harder. Meanwhile, this difficult time has also seen increased support for bereaved people from both informal and formal sources. The current increase in short-term support as because of COVID-19 should continue longerterm, highlighting the importance of ensuring available support for bereaved people's in ongoing life.

Despite the prospect of having increased and continuing support for bereaved people, the quantity and quality of support could vary across different settings. As well as individual differences, such as individual personality and interpersonal relationships, varied environments could play a significant role in shaping bereaved people's support networks and resources (Valentine, 2008). Differences between countries and regions and inequalities between races, classes and age groups could lead to diverse and complicated experiences of grief and bereavement. Therefore, it is impossible to find a universal answer to the above two hypotheses. Central to this dilemma, however, is the importance of developing a more sympathetic, inclusive and interdependent environment with grief literacy (Breen, et al., 2020). This approach emphasises a complex of resources and mechanisms enabling public and professionals to be more knowledgeable and proactively supportive in identifying and dealing with loss and grief. Such an environment resonates with the evidence and predictions highlighted in both hypotheses, serving to improve areas of insufficient support and to maintain and reinforce available resources. Thus, it could empower bereaved people, with different needs and from various backgrounds, to better facilitate grieving and make sense of their loss in community-based and day-to-day settings. The roles of policymakers, care 
providers, community leaders and social actors would be all indispensable for creating this grief literate culture in communities and wider society both during and post the outbreak (Kellehear, 2005; Breen, et al., 2020).

\section{Collective grief}

Responses to lives lost during COVID-19 may not only be individual but also collective in nature. The shared experience of loss and grief may contribute to the growing collective entities consisting of many thousands of mourners locally, nationally and even globally. Similar experiences of loss may enable mourners with similar experiences to form symbolic bonds with others, thus enabling grieving in a more collective sense. This sense of belonging could also be experienced in wider society, for both the bereaved and non-bereaved, as a collective response to loss in the face of COVID-19. When social members are lost and societal order is challenged, human groups typically resort to strengthening their collective bonds and consciousness, as a means of maintaining their social identity (Alexander, et al., 2004). This collective approach to loss and grief has been widely observed, ranging from the aforementioned small-scale 'yellow heart' movement to national mourning seen in numerous countries affected by COVID-19. An important question to better understand the phenomenon of collective grief is whether this has to be created through purposive strategies of idealisation of deaths and communal rituals, or whether it happens automatically as a mechanism to preserve society. This question could further indicate what is needed to deal with mass deaths and shared traumas in ongoing society.

Hypothesis 3: Collective grieving is a strategic response by society 
Collective responses to loss could be seen as a grieving process, assembling social members to face destruction and impairment and to reaffirm their conformity to society as an orderly and functional state. These processes could underline different strategies and purposes taken to deal with loss and grief at a societal level (Holst-Warhaft, 2010). Society as an entity tends to secure its stability and continuity in the face of mass deaths and social disorder. Public rituals and memorial activities can be prescribed as transitional and functional passages intentionally helping reaffirm shared values and social solidarity among social actors (Durkheim, 1912; van Gennep, 1960). One example is national mourning for COVID-19 victims held in China on $4^{\text {th }}$ April 2020. This state-led grieving response provided an opportunity to remember those lost and to reunite the country, thus helping it to move forward after the global crisis (BBC News, 2020a). Such events may be seen in other affected countries as collective and symbolic means of recharging the energy and confidence of society.

Such publicly organised commemoration activities are not necessarily temporary but may persist, shaping the continuing existence of society. These events can be intentionally repeated in relation to special tempo-spatial elements (Holst-Warhaft, 2000), such as annual remembrances for the 9-11 terrorist attacks in New York and memorial services at the mass burial sites for the 2011 Tōhoku earthquake victims in Japan. Similarly, significant locations and dates may be hallowed after the COVID-19 pandemic, to collectively and continuously reconstruct the past and to reinforce a communal sense of belonging for the future of society (Alexander et al., 2004). For example, New York City announced the use of a longmarginalised site, Hart Island, to bury COVID-19 virus victims (Sanchez, 2020). This burial ground may later become a special location because of the associated memories of mass death and crises. Therefore, how to manage and transform this site may play a significant role 
in reshaping the emotions of individual bereaved people and the public, allowing them to further negotiate and contest meanings both personally and collectively. Such publicly visible signs of this pandemic may appear elsewhere, presenting opportunities and challenges for both governments and communities, namely, how to transform collective pain and public emotions into meaningful shared memories of social solidarity and collective confidence.

Hypothesis 4: Collective grieving is a spontaneous response shared by individuals

An alternative approach to public anxiety and tension lies in voluntary individual actions. Given that the pandemic may challenge shared values and beliefs, individuals could spontaneously seek 'creative and highly idiosyncratic' ways to grieve their loss and ease their tension (Bradbury, 2001, p.221). These individual reactions may coincide, thus bringing grassroots grieving activities into being, such as the yellow-heart movement in the UK, used by bereaved families during this pandemic and the mass mourning after the death of Princess Diana. Similarly, many Chinese people adopted various ways to publicly mourn the death of Dr Li Wenliang in light of his invaluable contribution to society (Zhang, 2020). In addition, social media and dedicated memorial websites could provide alternative virtual platforms to create shared spaces to collectively acknowledge loss and grief. These online platforms could empower both the bereaved and non-bereaved to publicly legitimise and collectively alleviate their tension and grief (Harju, 2015). Ultimately, this could empower the public to create an online archive of reflective and meaningful lessons learnt from death and dying to reflect more broadly the resilience shown during this unprecedented pandemic. 
Collective grieving activities may be both extrinsically and intrinsically motivated during this pandemic. Despite this difference, needs for such shared responses to deaths and losses are clearly revealed. Responding to collective grief entails a duality of social functions and individual autonomy, underlining the socially mediated processes to deal with loss and grief at a societal level (Fang, 2019; Valentine, 2008). From a structural perspective, society, especially the authorities, may provide norms to allow for and regulate publicly acceptable emotions through public commemorations. These could serve to recover social order and solidarity following aggregate losses during COVID-19. In the light of individual agency, social members may coincide or deliberately plan to seek and create platforms to express their sorrow for collective loss and heroic individual deaths, further restoring their social identity. Both externally organised and spontaneous responses to collective grief have been documented during the outbreak and may continue to occur post this pandemic in various contexts. Collective grieving may sometimes become difficult and even impossible due to societies lacking the appropriate resources and structures to support these actions. For example, some authorities may not support public memorial events for politically sensitive deaths and some individuals may feel disfranchised to grieve for losses at a collective level. As such, it is essential to ensure available channels for both society as a whole and its members to restore meanings and an equilibrium in a collective and symbolic sense. The importance of social environments is again evident, calling for a resourceful, supportive and grief literate culture (Breen, et al., 2020). An environment of this nature could encourage society and individuals to negotiate meaningful ways to respond to the evident need for collective grief. Meanwhile, the shared experience of COVID-19 may further reinforce individual bereavement experiences by providing more established collective norms and values. 


\section{Concluding remarks and avenues for future research}

This article adopts a hypothetical approach to explore possible challenges and support for grief and bereavement in response to COVID-19. By examining relevant media outlets and existing scholarly writings, the discussion revisits and further relocates the ideas of good and bad deaths, grieving and bereavement support. These are examined in the context of the changing dynamics of social discourses and individual experiences as a result of this pandemic. Both good and bad deaths are explained and analysed to provide foundational understandings for the challenges and opportunities involved in deaths during COVID-19. A largely 'bad' nature of deaths is captured, often involving pain, loneliness, isolation and unexpectedness. 'Goodness' is seen through the heroisation of deaths, a socially mediated process to negate the highly disruptive nature of loss. In the face of the distressing nature of loss, experiences of grieving and bereavement may be significantly altered. Due to lockdown, social distancing and other new norms developed during this pandemic, pre-existing structures of mourning and grieving may become largely absent. This may require revised, compromised or completely new ways to grieve and to deal with bereavement. Despite lacking primary empirical data, it is still possible to develop a preliminary and exploratory view of grief and bereavement in this context. By using media coverage and relevant studies, diverse and even competing experiences of grief and bereavement are captured at both individual and collective levels. To better understand the complexity, two pairs of contrasting hypotheses are proposed to examine the impacts of COVID-19 on experiences of loss and support. As discussed, bereaved individuals may face both improved support or intensified challenges depending on their individual circumstances and social backgrounds. The social 
environment for grief and bereavement is found to be particularly important. This is also evident within in collective grieving experiences, in which relationships between broad structures and individual agency could powerfully shape the means of shared responses to deaths and losses.

Despite the complexity, two primary findings are confirmed through the hypotheses. These are, that both individuals and collectives have diverse needs in response to deaths and losses as part of the meaning-making process and that socio-cultural environments play a significant role in this process. How to better respond to these fundamental needs is closely associated with the social environments in which they are situated. As such, better support for grief and bereavement requires a grief literate environment, to allow for mutual understandings and interdependent support both in individual bereaved people's day-to-day settings as well as in broader society (Breen, et al., 2020). Based on a wider framework of compassionate communities, the emphasis on 'grief literate' environments lies in the empowerment of communities in response to increasing professionalisation and inequalities in bereavement support (Kellehear, 2005). To create a grief literate environment at different levels would require a rigorous approach during and post the COVID-19 outbreak. Local communities should continuously play a significant role in developing relevant resources and structures to better seek and negotiate appropriate means for dealing with loss. Further, a more inclusive and individualised approach is needed to develop community-based support, responding more directly to the diverse values of grief and bereavement for individuals from different social, religious, ethical, age and gender groups. Self-help groups in a non-psychotherapeutic setting could provide an invaluable model for mutual understandings and support among bereaved people with similar backgrounds and experiences. This model could also enable 
more context-specific grief literacy in wider compassionate communities and society. Meanwhile, support and guidance from both the public and professional resources, such as the government, social and health care professionals, are equally important. These more formalised support frameworks could complement and reinforce community-based support. This cooperation would allow for a 'new' structure of bereavement support to form and grow in the changed world following COVID-19.

Based on the assumptions and findings, an agenda is set to inform future research and to guide policy provision and care practice. In the light of the above hypotheses, a key question to ask in future inquires is: What is needed in response to deaths and losses and how do social environments support or undermine these needs in the context of significant crises and social restrictions. Future research should employ both quantitative and qualitative approaches to clarify the enablers and barriers in individual and collective grief experiences, also exploring relevant support. These enablers and barriers should also be examined within the context of minority and disadvantaged groups within the broader population. Further investigations on bereavement for particular demographic groups, such as children, adolescents and older people, are both important and necessary to understand the impacts of COVID-19 on the social constructions of loss and grief. In addition, studies on collective responses to deaths as a result of COVID-19 could offer powerful and creative insights into the ongoing debates on public mourning and memorialisation. The ideas of grief literate societies and compassionate communities are worth further consideration, to explore how community-based support could complement pre-established statutory support during pandemics and other major emergency events. Meanwhile, the importance of language and other socially accessible tools, such as the arts, should also be considered in policy-making and care provision. This approach 
may provide more accessible resources for bereaved people to deal with their loss and grief during and post the outbreak. This article could provide a base from which to assess the impact of pandemics and disruptive world events on grief and bereavement more broadly.

\section{References}

Alexander, J. C., Eyerman, R., Giesen, B., Smelser, N. J. and Sztompka, P. (2004), Cultural Trauma and Collective Identity. Berkeley, Carlifornia: University of California Press.

Alcorn, G. (2020), 'It was quite intimate': a tiny funeral for a big family man. The Guadian. $7^{\text {th }}$ April, available at https://www.theguardian.com/news/2020/apr/07/it-was-quiteintimate-a-tiny-funeral-for-a-big-family-man

Aloi, J. A. (2011), A Theoretical Study of the Hidden Wounds of War: Disenfranchised Grief and the Impact on Nursing Practice. International Scholarly Research Notices, 2011. doi:10.5402/2011/954081

American Psychological Association. (2020, APA COVID-19 Information and Resources Available at https://www.apa.org/topics/covid-19 (Accessed $1^{\text {st }}$ May 2020)

Atlani-Duault, L., Ward, J. K., Roy, M., Morin, C. and Wilson, A. (2020), Tracking online heroisation and blame in epidemics. The Lancet Public Health, 5(3), PE137-E138. doi:10.1016/S2468-2667(20)30033-5

Bachega, H. (2020), Coronavirus: Inside story of Spain's care home tragedy. BBC. $30^{\text {th }}$ April, available at https://www.bbc.co.uk/news/world-europe-52188820

BBC News. (2020a), Coronavirus: China mourns Covid-19 victims with three-minute silence. $B B C .4^{\text {th }}$ April, available at https://www.bbc.co.uk/news/world-asia-china-52162004 
BBC News. (2020b), Coronavirus: Close family to be allowed to say goodbye to the dying. BBC. $15^{\text {th }}$ April, available at https://www.bbc.co.uk/news/uk-52299590

BBC News. (2020), Coronavirus: Coming 5,000 miles to die for the NHS. BBC. $4^{\text {th }}$ April, available at https://www.bbc.co.uk/news/health-52152375

BBC News. (2020d), Coronavirus: outbreak "not yet at peak" and lockdown may last another month. $15^{\text {th }}$ April, available at https://www.youtube.com/watch?v=F5L-7p3v4GI

BBC News. (2020e), Coronavirus: Spanish army finds care home residents 'dead and abandoned'. BBC. 24 ${ }^{\text {th }}$ March, available at https://www.bbc.co.uk/news/worldeurope-52014023

BBC News. (2020f), Coronavirus: Why healthcare workers are at risk of moral injury. $B B C .6^{\text {th }}$ April, available at https://www.bbc.co.uk/news/world-us-canada-52144859

BBC News. (2020g), Coronavirus: Grieving together with a yellow heart. BBC. $16^{\text {th }}$ May, available at https://www.bbc.co.uk/news/av/uk-52589050/coronavirus-grievingtogether-with-a-yellow-heart

Bear, L., et al. (2020), 'A good death'during the Covid-19 pandemic in the UK: a report on key findings and recommendations. London School of Economics and Political Science, London, $27^{\text {th }}$ April

Bigelow, G. and Hollinger, J. (1996), Grief and AIDS: Surviving Catastrophic Multiple Loss. The Hospice Journal, 11(4), 83-96. doi:10.1080/0742-969X.1996.11882837

Bonanno, G. (2004), Loss, trauma, and human resilience: have we underestimated the human capacity to thrive after extremely aversive events? American psychologist, 59(1), 20-28.

Booth, R. (2020), Hundreds of UK care home deaths not added to official coronavirus toll. The Guardian. $9^{\text {th }}$ April, available at 
https://www.theguardian.com/world/2020/apr/09/covid-19-hundreds-of-uk-carehome-deaths-not-added-to-official-toll

Bradbury, M. (2001), Forget me not: Memorialization in cemeteries and crematoria. In J. L. Hockey, J. Katz, \& N. Small (Eds.), Grief, mourning and death ritual (pp. 218 - 225). Buckingham: Open University Press.

Breen, L., Kawashima, D., Joy, K., Cadell, S., Roth, D., Chow, A. and Macdonald, M. (2020), Grief literacy: A call to action for compassionate communities, Death Studies, DOI: $10.1080 / 07481187.2020 .1739780$

Cruse Breavement Care (2020), Coronavirus: dealing with bereavement and grief. Available at https://www.cruse.org.uk/get-help/coronavirus-dealing-bereavement-and-grief (Accessed 1st May 2020)

Davies, D. (2017), Death, Ritual and Belief: The Rhetoric of Funerary Rites: Bloomsbury Academic.

Dean, W., Talbot, S. and Dean, A. (2019), Reframing Clinician Distress: Moral Injury Not Burnout. Federal Practitioner, 36(10), 447.

Doka, K. J. (1989), Disenfranchised grief: recognizing hidden sorrow. Lexington, MA: Lexington Books.

Doss, E. (2008), The emotional life of contemporary public memorials: Towards a theory of temporary memorial. Amsterdam:: Amsterdam University Press.

Durkheim, E. (1912), The elementary forms of the religious life (2nd ed. ed.). London: Allen and Unwin.

Eligon, J. and Burch, A. (2020), Questions of bias in COVID-19 treatment add to the mourning for black families. New York Times. $10^{\text {th }}$ May, available at https://www.nytimes.com/2020/05/10/us/coronavirus-african-americans-bias.html 
Fang, C. (2019), Exploring social constructions of bereaved people's identity in mainland China: a qualitative approach. Mortality. doi: 10.1080/13576275.2019.1657389 Gennep, A. v. (1960), The rites of passage: Chicago : University of Chicago Press.

Goren, E. (2007), Society's Use of The Hero Following A National Trauma. American Journal of Psychoanalysis, 67, 37-52. doi:10.1057/palgrave.ajp.3350013

Handsley, S. (2001), "But what about us?" The residual effects of sudden death on selfidentity and family relationships,. Mortality, 6(1), 9-29. doi:10.1080/13576270020028610

Harju, A. (2015), Socially shared mourning: construction and consumption of collective memory. New Review of Hypermedia and Multimedia,, 21(1-2), 123-145. doi:10.1080/13614568.2014.983562

Holst-Warhaft, G. (2000), The cue for passion: grief and its political uses. Cambridge, Mass. Cambridge: Harvard University Press.

Huang, C., Wang, Y., Li, M., Xingwang, Ren, L., Zhao, J. and Hu, Y. (2020), Clinical features of patients infected with 2019 novel coronavirus in Wuhan, China. The Lancet. doi:10.1016/S0140-6736(20)30183-5

ITV News. (2020a), Coronavirus: 13-year-old with Covid-19 'died alone' without his family around him, friend says. $3^{\text {rd }}$ April, available at https://www.itv.com/news/2020-0401/coronavirus-13-year-old-victim-died-alone-friend-says-ismail-mohamedabdulwahab-kings-college-hospital/

ITV News. (2020b), The much-loved faces behind the stats: Families pay tribute to UK coronavirus vicitms. $31^{\text {st }}$ March, available at https://www.youtube.com/watch?time_continue=73\&v=k9iaK7Bazgg\&feature $=e m b$ _title 
ITV News. (2020c), People use freedom in coronavirus epicentre Wuhan to queue at cemeteries as travel restrictions ease. ITV News. $26^{\text {th }}$ March, available at https://www.itv.com/news/2020-03-26/coronavirus-outbreak-wuhan-epicentrepeople-queue-cemeteries-hubei-province-travel-restrictions/.

Kellehear, A. (2005), Compassionate Cities: Public Health and End of Life Care. London: Routledge .

Kellehear, A. (2007), A Social History of Dying. Cambridge: Cambridge University Press.

Lathrop, D. (2017), Disenfranchised Grief and Physician Burnout. Annals of Family Medicine, 15(4), 375-378. doi:10.1370/afm.2074

Lawton, J. (2000), The Dying Process: Patients' Experiences of Palliative Care. London: Routledge.

McCann, N. (2020). Coronavirus: No wake, no funeral, just prayers in a cemetery. $B B C .1^{\text {st }}$ April, available at https://www.bbc.co.uk/news/uk-northern-ireland-52106863 Meier, E. A., Gallegos, J. V., Montross-Thomas, L. P., Depp, C. A., Irwin, S. A. and Jeste, D. V. (2017), Defining a Good Death (Successful Dying): Literature Review and a Call for Research and Public Dialogue. American journal of geriatric psychiatry, 24(4), 261271. doi:10.1016/j.jagp.2016.01.135

Monella, L. M. (2020, 13th March 2020). Coronavirus: Italy doctors 'forced to prioritise ICU care for patients with best chance of survival'. euronews. Retrieved from https://www.euronews.com/2020/03/12/coronavirus-italy-doctors-forced-toprioritise-icu-care-for-patients-with-best-chance-of-s

Morelli, M., Cyrus, G., Weissbecker, I., Kpangbai, J., Mallow, M., Leichner, A., . . . euchte, F. (2019), Recovering from the Ebola crisis: 'Social Reconnection Groups' in a rural Liberian community. Global mental health, 6(e17). doi:10.1017/gmh.2019.13 
Neimeyer, R. A. (2011), Reconstructing Meaning in Bereavement. Estudos de Psicologia, 28(4), 421-426.

Office for National Statistics (2020), Coronavirus and the social impacts on Great Britain. Statistical bulletin. Availbale at https://www.ons.gov.uk/peoplepopulationandcommunity/healthandsocialcare/heal thandwellbeing/bulletins/coronavirusandthesocialimpactsongreatbritain/29may202 0 (Accessed $14^{\text {th }}$ May 2020)

O'Rourke, T., Brian H. Spitzberg and Annegret F. Hannawa (2011), The Good Funeral: Toward an Understanding of Funeral Participation and Satisfaction, Death Studies, 35:8, 729-750, DOI: 10.1080/07481187.2011.553309

Pace, J. C. and Mobley, T. S. (2016). Rituals at End-of-Life. Nursing Clinics, 51(3), 471 - 487. doi:10.1016/j.cnur.2016.05.004

Public Health England (2020), Disparities in the risk and outcomes of COVID-19. Public Health England, London. June 2020, available at https://assets.publishing.service.gov.uk/government/uploads/system/uploads/attac hment data/file/889195/disparities review.pdf.

Ramsay, S. (2020). Coronavirus: 'Everyone dies alone': Heartbreak at Italian hospital on brink of collapse. Sky News. $21^{\text {st }}$ March, available at https://news.sky.com/story/coronavirus-everyone-dies-alone-heartbreak-at-theitalian-hospital-on-the-brink-of-collapse-11961130

Riches, G. and Dawson, P. (2000), An intimate loneliness : supporting bereaved parents and siblings. Buckingham: Buckingham : Open University Press. 
Sanchez, R. (2020), NYC's Hart Island and coronavirus: 'A meaningful place in a dark time'. CNN. $12^{\text {th }}$ April, available at https://edition.cnn.com/2020/04/11/us/hart-islandcoronavirus-burials/index.html

Seale, C. (1995), Heroic Death. Sociology, 29(4), 597-613. doi.org/10.1177/0038038595029004003

Seale, C. (2004), Media constructions of dying alone: a form of 'bad death'. Social Science \& Medicine, 58(5), 967-974. doi:10.1016/j.socscimed.2003.10.038

Siddique, H. and Marsh, S. (2020). Coronavirus: Britons saying final goodbyes to dying relatives by videolink. The Guardian. $24^{\text {th }}$ March, available at https://www.theguardian.com/world/2020/mar/24/britons-saying-final-goodbyes$\underline{\text { to-dying-relatives-by-videolink-covid-19 }}$

Turner, N. and Caswell, G. (2019), Moral ambiguity in media reports of dying alone. Mortality. doi:10.1080/13576275.2019.1657388

Valentine, C. (2008), Bereavement narratives: Continuing bonds in the twenty-first century. Oxford: Routledge.

Valentine, C. (2009), Negotiating a loved one's dying in contemporary Japanese society. Mortality, 14(1), 34-52. doi:10.1080/13576270802591269

Valentine, C. (2010), Identity and the Good Death in the Narratives of Bereaved Japanese People. Grief Matters: The Australian Journal of Grief and Bereavement, 13(3), 82-86.

Valentine, C. (Ed.s) (2017), Families Bereaved by Alcohol or Drugs: Research on Experiences, Coping and Support. London: Routledge.

Walter, T. (1996), A new model of grief: Bereavement and biography. Mortality, 1(1), 7-25. doi:10.1080/713685822 
Walter, T. (1999), On bereavement the culture of grief: Buckingham England: Open University Press.

Walter, T. (2012), How people who are dying or mourning engage with the arts. Music and Arts in Action, 4(1), 73-98.

Walter, T. (2020), Death in the Modern World. London: Sage Publications.

Ward, V. (2020). Coronavirus survivor describes tragedy of patient who cried out for his family before dying alone. The Telegraph. $7^{\text {th }}$ April, available at https://www.telegraph.co.uk/news/2020/04/07/coronanvirus-survivor-describestragedy-patient-cried-family/

World Health Organisation (2020), Coronavirus disease (COVID-19) Pandemic. Available at https://www.who.int/emergencies/diseases/novel-coronavirus-2019 (Accessed 1st May 2020)

Zhang, H. (2020), Grief and Wariness at a Vigil for Li Wenliang, the Doctor Who Tried to Warn China About the Coronavirus. The New Yorker. $11^{\text {th }}$ Feburary, availabel at https://www.newyorker.com/news/news-desk/grief-and-wariness-at-a-vigil-for-liwenliang-the-doctor-who-tried-to-warn-china-about-the-coronavirus 